\title{
STRATEGY AND THE HYBRID STRUCTURE OF ECOSYSTEMS
}

\author{
Lesław PIETREWICZ \\ Institute of Economics, Polish Academy of Sciences, Warsaw; pietrewi@inepan.waw.pl, \\ ORCID: 0000-0002-6784-0771
}

Purpose: Despite the recent surge of interest in the concept of business ecosystem its nature remains poorly understood, with various conceptualizations developed in separate streams of literature. The aim of the paper is to develop an integrated perspective on ecosystems that would help managers better understand changing organizational landscape and inform strategic decision making.

Design/methodology/approach: The paper is built on a narrative conflict between the conceptualizations of business ecosystem as either firm environment or governance structure, and on discrepancy in treatment of coordination and other strategic interactions. We first map out the conceptual landscape of the topic, comparing ecosystems with alternative arrangements (industries, and markets and hierarchies, respectively). Then we introduce and apply the concept of strategic interactions as a novel theoretical perspective to design an integrated framework of business ecosystems.

Findings: Firm-level strategic interactions (competition, cooperation and coordination) taking place in the ecosystem (viewed as a form of environment) can and should get into strategic interactions with ecosystem-level coordination mechanisms (ecosystem as a governance structure), affecting on the one hand competitiveness of individual members of the ecosystem and the whole structure, and, on the other, boundaries of the ecosystem.

Research limitations/implications: Propositions concerning the interface between firm-level strategic interactions and ecosystem-level governance open up new lines of inquiry for management and organizational scholars and computer scientists, and invite their cooperation, e.g. in algorithmic governance.

Practical implications: Richer understanding of the nature of ecosystems helps managers make better informed strategic decisions concerning the nature of relations with other organizations.

Originality/value: The paper presents new theoretical arguments on the hybrid nature of ecosystems. It emphasizes an increased role of coordination in strategy and ecosystem development and calls for its wider coverage by strategy scholars.

Keywords: business ecosystem, ecosystem strategy, ecosystem governance, industry, strategic interaction.

Category of the paper: Conceptual paper. 


\section{Introduction}

In recent years, the concept of ecosystems has become one of the most fashionable ideas in management (Adner, 2017). Despite being widely used, its nature remains poorly understood, with the theory of ecosystems still at an early stage of development (Jacobides, Cennamo and Gawer, 2018; Stańczyk-Hugiet, 2015). Viewed in different streams of literature as either a type of network (e.g. Iansiti and Levien, 2004), governance structure separate from markets, hierarchies, alliances, networks, etc. (Moore 1996; Wareham, Fox and Cano Giner, 2014), or a new way to depict the competitive environment (Jacobides et al., 2018), it evades precise categorization and unequivocal definition (Makinen and Dedehayir, 2012). The popularity of the term, however, suggests that the concept is needed and further conceptual work is required to advance our understanding and build consensus on the meaning of the term.

The aim of the paper is to develop an integrated perspective on ecosystems. We model ecosystem as a hybrid structure of (1) an arena of strategic interactions, replacing industry, and (2) a governance structure alternative to hierarchies and markets. We posit that the competitive arena (i.e. firm environment) and the governance structure (i.e. organizational) aspects of ecosystem not only complement each other - as can be readily conjectured based on the extant literature - but condition, permeate and constitute each other to the point that one cannot be properly understood without doing justice to the other.

To be sure, consolidation and integration of the diverse perspectives on ecosystems have been attempted before (e.g. Anggraeni, Hartigh and Zegveld, 2007; Baghbadorani and Harandi, 2012; Jacobides et al., 2018). What distinguishes our approach is choosing strategic interactions as a basis for integration. We propose to regard the "new competitive environment" (Jacobides et al., 2018) aspect of ecosystem as an arena of not only competitive interactions but also of cooperation and coordination. Strategic interactions - conflict (competition), cooperation and coordination - are interactions in which outcomes of one actor's decision depend on decisions by other actors (Hardin, 1990), and the rationale behind considering them jointly is that any single type of strategic interactions does not take place in isolation from the other types of strategic interactions. Rather than that, they are closely interlinked, to the point of finding it pertinent to give the simultaneous use of competition and cooperation a new term of coopetition (e.g. Czakon, Mucha-Kuś and Rogalski, 2014; Luo, 2007). Moreover, cooperation requires coordination and is accompanied by it, and even actors with conflicting interests may coordinate actions (Malone and Crowston, 1990), if they engage in coopetition, for example in adopting technology in standard wars (Augereau, Greenstein and Rysman, 2006). Finally, not only competition and cooperation, but also coordination can and should be analysed from the strategic management perspective as the choice of coordination mechanisms (tools) can affect effectiveness of cooperative and coopetitive strategies (Malone and Crowston, 1990) and be a source of competitive advantage. 
Coordination interactions attracted scant attention of strategy scholars, despite their prevalence in interfirm interactions and their strategic significance. The topic has developed into a separate research area focused on managing dependencies between activities and organizations (e.g. Malone and Crowston, 1994), but it is in contract theory and the context of ownership arrangements (i.e. make-or-buy decisions, or the problem of vertical integration) that the topic of coordination has attracted most interest.

In the latter, governance perspective (and the transaction cost economics which contributed most to its development), coordination is viewed as achieved by either hierarchy (i.e. authority) or market (i.e. price) mechanisms, which translates into make or buy decisions, respectively (Coase, 1937). With the advancement of the field, additional governance mechanisms have been recognized, for example relational contracts (social coordination) (e.g. Williamson, 1985), viewed as leading to "ally" decisions (Baker, Gibbons and Murphy, 2002) or as affecting the depth of relationships in other governance structures (Macneil, 1983). From the governance perspective, organizational structures develop to better coordinate economic activities, and the rationale behind choosing governance mechanisms is based on the efficiency of coordination calculus.

Therefore, in the second aspect of our model we project ecosystem as a new governance structure. However, while traditionally the problem of coordination was portrayed as the vertical integration decision in the industry value chains (and the pipeline business models characteristic of industry architectures), in ecosystem architectures, which are built around platforms (and platform business models) (Iansiti and Richards, 2006; Van Alstyne, Parker and Choudary, 2016), the problem of coordination cannot be reduced to make or buy decisions of ecosystem participants as standardized rules of access and roles of participants are recognized as instrumental in achieving ecosystem coordination (Adner, 2017; Jacobides et al., 2018). They set the stage for the complex interplay between firm-level competition, cooperation and coordination interactions that fuel ecosystems which, in turn, can affect the rules. Thus, the traditional make or buy calculus transforms into a much more complex decision structure, with broader scope and more strategic options, and the problem of boundaries of the firm expands into the problem of boundaries of the ecosystem.

\section{Industries and ecosystems}

The idea of ecosystem as a new way to depict competitive environment has been gaining traction in recent years. Although Jacobides et al. (2018, p. 2274) viewed ecosystem as a "specific type of industry architecture", more typically it is argued to replace industry as a unit of analysis. For example, Moore (1993) argued that a firm should view itself not as a member of a single industry but as part of an ecosystem that spans industries, and Teece (2014) 
and Stańczyk-Hugiet (2015) claimed that ecosystem may substitute for industry for performing competitive analysis. Before substantiating this claim, it is pertinent to explain shortly what the traditional structure of an industry is. Industry is a level in economic taxonomy which organizes companies based on essential characteristics of technology and product markets (Peneder, 2003). Cambridge Dictionary defines industry as "the people and activities involved in one type of business". In an early academic definition Porter (1979) described it as a "group of competitors producing substitutes that are close enough that the behavior of any firm affects each of the others either directly or indirectly", which resonates with modern-day definition of competitive interactions. More recently, Hill and Jones (2009, p. 53) have defined industry as "a group of companies offering products or services that are close substitutes for each otherthat is, products and services that satisfy the same basic customer needs" (similarly in their 2008 book). Industry boundaries are defined by the degree of strategic interrelationship and the main purpose of drawing them is to conduct strategic analysis (Porter 1985).

Invariably, industries are depicted as segmentation units, distinguishable on the basis of closeness of substitutes and competitive interactions. The need for a new conceptualization of business environment and new segmentation principles, and the subsequent popularity of the new term and concept of ecosystems have their roots in the decreasing relevance of the concept of industry for strategic management. Reports on blurring, dissolving or falling of industry boundaries (e.g. Atluri, Dietz and Henke, 2017; Bughin et al., 2018; Kelly, 2015; McGrath, 2013) suggest that the traditional principles of segmentation are no longer valid. This observation can be related to a few developments. Firstly, digital technologies span industries, leading to digital newcomers with new business models causing the most serious threat to industry incumbents (Johnson, Christensen and Kagermann, 2008). Secondly, digitalization and growing complexity of technologies demands increasing specialization and enables modularization of technologies and fragmentation of value chains (Alcácer, Cantwell and Piscitello, 2016; Langlois, 2002). Since no company is able to advance technologies entirely in-house, without tapping external sources of knowledge (Alcácer et al., 2016), technological progress demands widespread cooperation and coordination of activities. Therefore, competitive interactions can no longer be viewed as determining success of a firm and, by the same token, as properly describing the nature of strategic interactions between economic actors. The place of individual firm in the structure depends on how well it fits in and complements activities of its partners. Hence, we model ecosystems as encompassing all firms whose success depends on the success of the whole structure (architecture), making the fates of individual actors interdependent. Whereas closeness of substitutes and competitive interactions were central to industries, in defining ecosystems the issue of complements and complementors comes to the fore, and the nature of complementarities defines the scope of ecosystems (Jacobides et al., 2018). In short, we consider both industries and ecosystems as segmentation units, however, with different segmentation rules. The summary of distinguishing characteristics is presented in Table 1. 
Table 1.

Comparison of industry and ecosystem architectures

\begin{tabular}{|l|l|l|}
\hline Architecture & Industry & Ecosystem \\
\hline Structure & Competitors & Complementors, technology modules, \\
\hline Distinctive strategic interaction & Competition & Cooperation and coordination \\
\hline Success & Individual firm efforts/atomistic & Intendedly co-determined \\
\hline Type of business model & pipeline & platform \\
\hline Focus of strategy & $\begin{array}{l}\text { Control over scarce, valuable } \\
\text { and inimitable resources }\end{array}$ & $\begin{array}{l}\text { Orchestrating resources, controlling } \\
\text { access }\end{array}$ \\
\hline Segmentation principles & Closeness of substitutes & Nature of complementarities \\
\hline
\end{tabular}

\section{Firms, markets and ecosystems}

Recent definitions of ecosystems put coordination at the centre as "alignment structures" ("the extent to which there is mutual agreement among the members regarding positions and flows" (Adner, 2017, p. 47)) and specific structures of relationships necessary to deal with complementarities to create value (Jacobides et al., 2018), which resonate well with the general definition of coordination as managing dependencies among activities which result from orientation at common or mutually agreed compatible goals (Malone and Crowston, 1990, 2012). While price (market) and authority (hierarchy) have traditionally been viewed as the main forms of coordinating business activities, in the last few decades other forms of coordination (i.e. governance structures) - clans, bureaus, networks, alliances, virtual organizations, regulation, etc. - have begun to attract increased academic attention. Ecosystems can be viewed as yet another governance structure, and their emergence as reflecting on the one hand new coordination possibilities, and on the other, new coordination needs.

As governance structures differ in their costs and competence (Williamson, 1998), the existence of various governance structures implies that different coordination needs demand different governance structures. By the same token, the emergence and growing importance of the new governance structure of ecosystems implies their alignment - better than in alternative governance structures - with the demands of coordination in the changing business environment.

The dramatic changes in the business landscape are typically viewed as having roots in advances in ICT, which reduce coordination costs and increase coordination possibilities by opening up new strategic and organizational possibilities (Adner, 2017). The logic of competitive advantage changes form ownership of scarce and valuable resources to orchestrating them (Van Alstyne et al., 2016) and integrating knowledge across organizational boundaries (Alcácer et al., 2016). Thus, the canonical coordination problem of vertical integration (i.e. using market or hierarchy coordination) gives way to new forms of integration, involving standardized rules of access to communities and their resources (knowledge in particular) and roles of their members (participants). The conventional coordination decision of 
make or buy (i.e. of integration based on ownership) gives way to a more complex structure focused on experimentation and integration of knowledge, making the boundaries unstable by design.

Present-day ecosystems are enabled by platforms acting as ecosystem leaders (Adner, 2017) and modular architectures, which allow a set of distinct yet interdependent organizations to coordinate through standardized sets of roles that face similar rules (Jacobides et al., 2018), namely governance rules regarding terms of access, incentives and control (Adner, 2017), without full hierarchical control (Jacobides et al., 2018). These new coordination capabilities allow ecosystems to go beyond the canonical choice of market interactions versus vertical integration. The summary of governance characteristics of markets, hierarchies and ecosystems is given in Table 2.

Table 2.

Comparison of selected forms of economic governance

\begin{tabular}{|l|l|l|l|}
\hline Governance structure & Market & Hierarchy (firm) & Ecosystem \\
\hline Normative basis & Property rights & Employment contracts & $\begin{array}{l}\text { Complementarity, } \\
\text { mutual adjustment }\end{array}$ \\
\hline $\begin{array}{l}\text { Main coordination } \\
\text { mechanism }\end{array}$ & Price & Authority & $\begin{array}{l}\text { Rules of access, roles of } \\
\text { participants }\end{array}$ \\
\hline Primary benefits & Flexibility & Control & $\begin{array}{l}\text { Generation and sharing } \\
\text { of knowledge }\end{array}$ \\
\hline Degree of flexibility & High & Low & Medium \\
\hline Form of integration & - & Ownership & Data, access, roles \\
\hline
\end{tabular}

\section{Integration and discussion}

As Jacobides et al. (2018, p. 2260) noted, “[f]or ecosystems to be useful, there must [...] exist a significant need for coordination that cannot be dealt with in markets, but which also does not require the fiat and authority structure of a central actor." Ecosystems combine elements of market and hierarchical arrangements by adopting modular production systems allowing interdependent companies to maintain autonomy and discretion over a number of issues such as design and prices, while providing them with a certain level of coordination in the form of standardized rules of access and governance which these companies have to follow. Thus, ecosystems provide a structure within which interdependencies can be contained and coordinated without the need for vertical integration (Jacobides et al., 2018). Ipso facto, ecosystems eschew the canonical choice of vertical integration versus non-integration, with their intrinsic costs and limitations (c.f. Williamson, 1985). The conventional coordination decision of make or buy (i.e. of integration based on ownership) gives way to a more complex structure focused on access to complementary resources and facilitating integration of knowledge of ecosystem participants with specific governance rules. 
As ecosystem leaders (typically central platform administrators) design the rules of the game for ecosystem members to follow, they set the stage for the complex interplay between firm-level strategic interactions - competition, cooperation and coordination - that fuel ecosystem operation and development. Since such rules differ in their efficacy, and data collected from and on ecosystem participants can be leveraged by the ecosystem leader to design better rules (i.e. better serving the whole community and the integrating structure), the strategic interactions between interdependent companies within ecosystem can and should affect the rules of future periods. In other words, firm-level strategic interactions taking place in the ecosystem (viewed as a form of environment) can get in strategic interactions with ecosystem-level coordination mechanisms (ecosystem as a governance structure), affecting on the one hand competitiveness of individual members of the ecosystem and the whole structure, and, on the other, boundaries of the ecosystem.

The most striking example of this mechanism comes from ecosystems developed around blockchain platforms, i.e. electronic platforms providing consensus protocols which enable recording and clearing any type of online transactions, potentially replacing traditional arrangements using a trusted third party guaranteeing transactions and collecting fees for its services. Individual blockchains codify their rules of access and governance, which their members have to follow. However, advancing technology and changing regulations occasionally require changing some of the rules. A distinctive characteristic of blockchain is that they are distributed platforms lacking central authority, and, what follows, change of rules involves voting of blockchain members (different rules apply), effectively giving members control over coordination rules (e.g. switching from the so-called proof-of-work to proof-ofstake consensus protocols).

Finally, in the world of ecosystems coordination comes to the fore of strategic thinking as decisive not only for determining the boundaries of ecosystems but also for their success. Rules of access and governance should be such as to engage partners by incentivizing them to bring valuable resources that would benefit the whole ecosystem; unrestricted access can destroy value by allowing misbehaviour or low quality content, and open governance can create misalignment (Van Alstyne et al., 2016). The strategic role of coordination is amplified by the turbulent business environment which puts speed and flexibility in front of efficiency and differentiation as sources of competitive advantage (Colville and Murphy, 2006). Such environment promotes ecosystem structures, credited for speeding up innovation and shortening time to market thanks to putting the problem of coordination at the forefront of strategizing (Colville and Murphy, 2006). The success of this new form of governance testifies to the strategic value of interrelating strategizing and organizing. 


\section{Conclusions}

Competition, cooperation and, more recently, coopetition, are conventionally seen as types of relations between business actors, or strategic approaches to building a position of competitive advantage within an industry. Similarly, coordination is viewed as an organizational process oriented at increasing effectiveness of either production processes (in firm as a production system approach) (e.g. Malone and Crowston, 1994) or transactions (in firm as a nexus of contracts and transaction cost economics approaches) (e.g. Wiliamson, 1985). This distinction - and the resulting separate treatment of strategic and organizational phenomena and processes - calls for an urgent reappraisal in the world of ecosystems as the two processes get interrelated and jointly determine the lots of the ecosystem and its participants.

In ecosystems the problem of coordination cannot be reduced to make or buy decisions as ecosystem-level rules of access and roles of participants are instrumental in achieving ecosystem coordination. These set the stage for the complex interplay with firm-level strategic interactions that fuel ecosystem development which, in turn, can - and should - affect the rules of governance. Thus, ecosystem-level coordination and firm-level strategic interactions (competition, cooperation, coopetition and coordination) come into complex interplay co-determining the boundaries of the ecosystem, its competitiveness, and competitiveness of its participants.

As a result, the boundaries of ecosystem change and the ecosystem gains extra swiftness and flexibility, allowing it to compete successfully with the more established - and stable governance structures. Hence, the emergence of ecosystems can be seen as a response to important competitive, collaborative, and organizational challenges faced by firms and, at the same time, inefficiencies of conventional hierarchical and market-based arrangements.

\section{References}

1. Adner, R. (2017). Ecosystem as structure: An actionable construct for strategy. Journal of Management, 43(1), 39-58. https://doi.org/10.1177/0149206316678451.

2. Alcácer, J., Cantwell, J., and Piscitello, L. (2016). Internationalization in the information age: A new era for places, firms, and international business networks? Journal of International Business Studies, 47(5), 499-512. https://doi.org/10.1057/jibs.2016.22.

3. Anggraeni, E., Hartigh, E., and Zegveld, M. (2007.10.19-21). Business ecosystem as a perspective for studying the relations between firms and their business networks. Paper presented at the ECCON 2007 Annual meeting, Bergen an Zee, Netherlands. 
4. Atluri, V., Dietz, M., and Henke, N. (2017). Competing in a world of sectors without borders. McKinsey Quarterly. Retrieved from https://www.mckinsey.com/businessfunctions/mckinsey-analytics/our-insights/competing-in-a-world-of-sectors-withoutborders, 2019.06.02.

5. Augereau, A., Greenstein, S., and Rysman, M. (2006). Coordination versus differentiation in a standards war: 56K modems. The RAND Journal of Economics, 37(4), 887-909. https://doi.org/10.1111/j.1756-2171.2006.tb00062.x.

6. Baghbadorani, M., and Harandi, A. (2012). A Conceptual Model for Business Ecosystem and for Implications Future Research, https://pdfs.semanticscholar.org/5cf7/26125eb04a9677e217c3f9ec2039591ebb4c.pdf.

7. Baker, G., Gibbons, R., and Murphy, K. (2002). Relational Contracts in Strategic Alliances, Unpublished Working Paper, http://www.people.hbs.edu/gbaker/oes/papers/BGM 2_26_02.pdf 2019.05.31.

8. Bughin, J., Catlin, T., Hirt, M., and Willmott, P. (2018). Why digital strategies fail. McKinsey Quarterly, January. https://www.mckinsey.com/business-functions/digitalmckinsey/our-insights/why-digital-strategies-fail_2019.04.02.

9. Catlin, T. Lorenz, J., Nandan, J., Sharma, S., and Waschto, A. (2018). Insurance beyond digital: The rise of ecosystems and platforms. https://www.mckinsey.com/industries/ financial-services/our-insights/insurance-beyond-digital-the-rise-of-ecosystems-andplatforms, 2019.04.02.

10. Coase, R. (1937). The nature of the firm. Economica, 4, 386-405.

11. Colville, I., and Murphy, A. (2006). Leadership as the Enabler of Strategizing and Organizing. Long Range Planning, 39, 663-677. doi:10.1016/j.lrp.2006.10.009.

12. Czakon, W., Mucha-Kuś, K., and Rogalski, M. (2014). Coopetition research landscape a systematic literature review 1997-2010. Journal of Economics \& Management, 17, 122-150.

13. Hardin, R. (1990), The Social Evolution of Cooperation. In: K. Cook and M. Levi (Eds.), The Limits of Rationality (pp. 358-382). Chicago-London: The University of Chicago Press.

14. Hill, C., and Jones, G. (2008). Strategic Management: An Integrated Approach. BostonNew York: Houghton Mifflin Company.

15. Hill, C., and Jones, G. (2009). Essentials of Strategic Management. South-Western Cengage Learning.

16. Iansiti, M., and Levien, R. (2004). Strategy as Ecology. Harvard Business Review, 82(3): 68-78.

17. Iansiti, M., and Richards, G. (2006). Information Technology Ecosystem: Structure, Health, and Performance. Antitrust Bulletin, 51(1), 77-110. https://doi.org/10.1177/ 0003603 X0605100104.

18. Jacobides, M., Cennamo, C., and Gawer, A. (2018). Towards a theory of ecosystems. Strategic Management Journal, 39, 2255-2276. https://doi.org/10.1002/smj.2904. 
19. Johnson, M., Christensen, C., and Kagermann, H. (2008). Reinventing Your Business Model. Harvard Business Review, 86(12), 50-59.

20. Kelly, E. (2015). Introduction: Business ecosystems come of age, Deloitte Insights, http://dupress.deloitte.com/dup-us-en/focus/business-trends/2015/business-ecosystemscome-of-age-business-trends.html, 2019.05.10.

21. Langlois, R. (2002). Modularity in technology and organization. Journal of Economic Behavio \& Organization, 49, 19-37.

22. Luo, Y. (2007). A coopetition perspective of global competition. Journal of World Business, 42(2), 129-144. https://doi.org/10.1016/j.jwb.2006.08.007.

23. Macneil, I. (1983). Values in contract: Internal and external. Northwestern University Law Review, 78(2), 340-418.

24. Makinen, S., and Dedehayir, O. (2012). Business ecosystem evolution and strategic considerations: A literature review. 18th International ICE Conference, Munich, Germany, DOI: 10.1109/ICE.2012.6297653.

25. Malone, T., and Crowston, K. (1990). What is Coordination Theory and How Can It Help Design Cooperative Work Systems. Proceedings of the Conference on Computer Supported Cooperative Work. Los Angeles, CA.

26. Malone, T., and Crowston, K. (1994). The Interdisciplinary Study of Coordination. ACM Computing Surveys, 26(1), 87-119.

27. Malone, T., and Crowston, K. (2012). The Interdisciplinary Study of Coordination. In: G. Olson, T. Malone and J. Smith (Eds.), Coordination Theory and Collaboration Technology (pp. 7-50). New York-Hove: Psychology Press.

28. McGrath, R. (2013). The End of Competitive Advantage: How to Keep Your Strategy Moving as Fast as Your Business. Boston: Harvard Business Review Press.

29. Moore, J. (1993). Predators and Prey: A New Ecology of Competition. Harvard Business Review, 71(3), 75-86.

30. Moore, J. (1996). The Death of Competition: Leadership and Strategy in the Age of Business Ecosystem. John Wiley \& Sons, Ltd.

31. Peneder, M. (2003). Industry Classifications: Aim, Scope and Techniques. Journal of Industry, Competition and Trade, 3(1-2), 109-129. https://doi.org/10.1023/ A:1025434721292.

32. Porter, M. (1979). The Structure within Industries and Companies' Performance. The Review of Economics and Statistics, 61(2), 214-227. DOI: 10.2307/1924589.

33. Porter, M. (1985). Competitive Advantage: Creating and Sustaining Superior Performance. New York: The Free Press.

34. Stańczyk-Hugiet, E. (2015). Strategicznie o ekosystemie biznesu. Prace Naukowe WWSZiP, 32(2), 395-409.

35. Teece, D. (2014). Business ecosystems. In: M. Augier and D. Teece (Eds.), Palgrave Encyclopedia of Management. https://doi.org/10.1057/9781137294678.0190. 
36. Van Alstyne, M., Parker, G., and Choudary, S. (2016). Pipelines, Platforms, and the New Rules of Strategy. Harvard Business Review, 94(4), 54-62.

37. Wareham, J., Fox, P., and Cano Giner, J. (2014). Technology ecosystem governance. Organization Science, 25(4), 1195-1215. https://doi.org/10.1287/orsc.2014.0895.

38. Williamson, O. (1985). The Economic Institutions of Capitalism: Firms, Markets, Relational Contracting. New York: The Free Press.

39. Williamson, O. (1998). Transaction Cost Economics: How It Works, Where It is Headed. De Economist, 146(1), 23-58. h 